\title{
Gestión económica e impuesto a la renta
}

Humberto Medrano Cornejo

Abogado por la Pontificia Universidad Católica del Perú.

Profesor de la Facultad de Derecho de la Pontificia Universidad Católica del Perú. Integrante de la comisión que redactó la Ley del Impuesto a la Renta y su reglamento.

SUMARIO:

I. Limitación a la deducción de intereses.

II. Definición legal del concepto de devengo.

III. Enajenación indirecta de acciones. 


\section{RESUMEN:}

El Congreso delegó en el Poder Ejecutivo la facultad de legislar sobre gestión económica y competitividad, precisando que la autorización abarcaba materia tributaria y, dentro de esta, las normas relativas a la deducción de gastos en las rentas de tercera categoría, a fin de que no se utilicen indebidamente para generar escudos fiscales o financiar requerimientos personales. Igualmente, se podía modificar el régimen de transferencia indirecta de acciones e incorporar una definición legal del concepto "devengo", a fin de contar con una regulación jurídica específica, que evite las imprecisiones que suelen producirse desde otras perspectivas.

En este artículo se analiza el alcance de los cambios introducidos, respecto de los mencionados extremos.

Palabras clave: gestión económica, competitividad, materia tributaria, rentas de tercera categoría, Enajenación indirecta de acciones, devengo.

\footnotetext{
ABSTRACT:

Congress delegated the power to legislate on economic management and competitiveness to the Executive Branch, specifically, said authorization covered tax matters and, within this, rules relating to the deduction of expenses in portfolio income, so that the aforementioned are not improperly used to generate tax shields or finance personal requirements. Likewise, the indirect share transfer regime could be modified and a legal definition of the concept of "accrual" could be incorporated, in order to have a specific legal regulation that avoids the inaccuracies that usually occur from other perspectives.

This article analyzes the scope of the changes introduced, in respect to the aforementioned extremes.

Keywords: tax, portfolio income, accrual, competitiveness, tax law, indirect share transfer.
}

\section{LIMITACIÓN A LA DEDUCCIÓN DE INTE- RESES}

La Organización la Cooperación y Desarrollo Económicos - OCDE ha preparado un conjunto de medidas contra la Erosión de la Base Imponible y el Traslado de Beneficios - Base Erosion and Profit Shifting-BEPS-. Entre ellas, la que se denomina Acción 4 está dirigida a limitar el uso de deuda entre entidades vinculadas y con terceros para evitar la excesiva deducción de intereses.

Sobre el particular debe recordarse que en nuestro país, desde hace muchos años, la Ley del Impuesto a la Renta ha previsto ciertas restricciones a las empresas para descontar de la materia imponible este tipo de egresos.

Así, por ejemplo, para esos fines solo se admiten como gasto los intereses adeudados en la parte que excedan de los intereses exonerados o inafectos que se perciban, con algunas excepciones. La razón es que si un contribuyente tiene recursos como para efectuar inversiones que le generan ingresos no sujetos al tributo, resulta fiscalmente inaceptable que contraiga deudas que den lugar a cargos financieros susceptibles de deducirse de la renta bruta.

Pero, adicionalmente, la ley establecía que en los endeudamientos con partes vinculadas solo era posible deducir los intereses generados por créditos que no excedieran tres veces el patrimonio neto del contribuyente al cierre del ejercicio anterior. El propósito era incidir en las situaciones genéricamente denominadas subcapitalización, donde las operaciones entre entidades relacionadas permitirían reducir la renta gravable. Sin embargo, conviene destacar que si la tasa aplicable y la forma de calcular la materia imponible son las mismas para ambos contribuyentes, el efecto sería neutro en términos de recaudación pues el gasto para uno supondría ingreso para el otro, salvo que medien situaciones especiales como la existencia de pérdidas no compensadas.

En cambio, la finalidad antielusiva de la regla se cumpliría claramente si se tratara de un crédito otorgado a la sociedad por un accionista persona natural domiciliada; pues en ese caso, al deducirse los intereses como gasto, el negocio dejaría de tributar sobre esa parte la tasa em- 
presarial —actualmente $29.5 \%$-, mientras que el acreedor persona natural por la renta que perciba debe hacerlo con una alícuota más reducida -actualmente $5 \%$ -

El Poder Ejecutivo mediante Decreto Legislativo 1424 ha incorporado algunos cambios significativos respecto de esta materia. En la exposición de motivos se indica que:

"las normas del impuesto a la renta otorgan un tratamiento diferenciado al rendimiento de la deuda y del capital. Los gastos financieros generados por la deuda son deducibles, mientras que los dividendos y otras formas de distribución de utilidades no lo son. Esta diferencia puede afectar la decisión que los contribuyentes tomen respecto de la proporción de deuda/capital con la que financiarán a una empresa".

En efecto, a fin de aprovechar las ventajas tributarias y sin tener en cuenta razones referidas al negocio, los accionistas podrían optar por realizar aportes de capital encubiertos mediante la asignación de recursos a una sociedad bajo la modalidad de un préstamo. Es claro que no existe impedimento civil o mercantil para que los socios lleven a cabo esa clase de operaciones con la empresa que integran, ya que la regulación está dirigida únicamente al ámbito impositivo.

La citada limitación a tres veces el patrimonio neto del ejercicio anterior, se mantiene respecto de todos los créditos existentes al 13 de setiembre de 2018, fecha de publicación de la referida norma legal, pero esta ha introducido dos cambios importantes. El primero está vinculado con las deudas contraídas a partir del 14 de setiembre de 2018, disponiéndose que la prohibición de deducir los intereses por la parte de tales obligaciones que exceda de tres veces el patrimonio neto del ejercicio anterior, se aplicará no solo con relación a los créditos entre partes vinculadas sino también cuando se trate de endeudamientos con terceros no relacionados. Como puede apreciarse, se ha extendido de manera considerable el radio de acción de la norma, lo cual obligará que las empresas tomen en cuenta este límite de manera general; esto es aun cuando los créditos fueran otorgados por entidades cuyo giro sea, precisamente, el financiamiento de las operaciones de empresas privadas, como ocurre con los bancos locales o extranjeros, que son completamente ajenos - directa o indirectamente- al capital o administración de la sociedad prestataria y, por lo tanto, no podría presentarse el supuesto de una menor recaudación tributaria por el conjunto de la transacción.

Para una empresa con pocas posibilidades de conseguir aportes al capital social, esta medida puede dar lugar a un apreciable aumento en el costo financiero de las actividades del negocio lo que, obviamente, implicaría la disminución de sus utilidades comerciales, pero -en razón del límite a la deducción - un incremento de la renta gravable, de manera que por generar tales consecuencias, la norma no parecería adecuada para la realidad de nuestro medio.

Planteadas así las cosas, ya no resultaría válido sostener que estamos frente a un mecanismo para impedir la elusión en forma directa, puesto que el diseño legal adoptado resultará aplicable a pesar de que lograra demostrarse fehacientemente que entre la empresa examinada y sus acreedores no existe vínculo alguno. En efecto, la exposición de motivos ${ }^{1}$ indica que:

"aun cuando las normas del impuesto a la renta limitan la deducción de intereses provenientes de endeudamiento entre partes vinculadas, la evidencia internacional señala que los contribuyentes pueden adoptar esquemas complejos bajo los cuales no es posible verificar si se están realizando operaciones entre partes vinculadas tales como las denominadas back to back".

Ello confirma que estamos frente a una regulación cuyo propósito es imponer el límite porque 
podría existir nexo orgánico entre las partes, pero como quiera que algunas veces no es posible demostrarlo, se ha optado por una restricción absoluta que resulta cuestionable. En nuestra opinión, habría sido deseable permitir que el contribuyente pueda probar la ausencia de vínculo entre los otorgantes y los solicitantes del crédito, hipótesis en la cual no debería ser aplicable la restricción.

A fin de evitar las prácticas que se critican, se ha visto que en la legislación comparada varios países -España y Colombia- limitan la deducción de intereses por endeudamientos tanto entre partes vinculadas como con terceros. Sin embargo, todavía un número significativo de ordenamientos legales se contrae sólo a los casos en que existe relación entre acreedores y deudores; esto es, se han enfocado exclusivamente en los supuestos en que pudiera presentarse una forma de elusión.

El segundo cambio sobre esta materia es aún más significativo, pues varía la naturaleza del factor que sirve de referencia para restringir el gasto, modificación que entrará en vigencia a partir del ejercicio 2021. Desde ese año, no serán deducibles los intereses netos en la parte que excedan el treinta por ciento del EBITDA del ejercicio anterior.

Se define EBITDA como la renta neta luego de efectuada la compensación de pérdidas más los intereses netos, depreciación y amortización.

Ahora bien, los intereses netos que no hubieran sido deducidos por exceder el límite, podrán ser adicionados a aquellos correspondientes a los cuatro ejercicios inmediatos siguientes, lo que puede considerarse como un modo de compensar los efectos negativos de la norma, puesto que los mayores intereses y la menor renta no necesariamente son causados por deficiencias en el manejo de la empresa sino que pueden deberse a múltiples razones. Por ello, resulta plenamente justificada la posibilidad de "arrastrar" el saldo de gastos por intereses no aplicados por razones de cuantía. Si bien es cierto que podría cuestionarse el plazo que se otorga, es claro que esta variante alivia el rigor de la disposición.
Debe notarse que la aplicación del mecanismo descrito podría suponer que los gastos por intereses no necesariamente resultarán afectando al ejercicio en que se devengaron sino que, por las causas indicadas, la incidencia en la renta imponible se produciría en los ejercicios posteriores.

La exposición de motivos señala que

"se ha optado por tomar el EBITDA dado que este refleja qué tan rentable es un negocio sin verse afectado por los intereses, depreciaciones y amortizaciones. Se propone que este EBITDA sea construido sobre base tributaria a fin de evitar que sea manipulado para incrementar el límite".

La posición expuesta permite concluir que ese factor de referencia no evidenciará - necesariamente - la rentabilidad del negocio, como se sostiene en una parte de la justificación que se ensaya, pues habrá ciertos gastos reales que, por no ser deducibles para fines impositivos, no se tomarán en cuenta para establecer el exacto rendimiento empresarial y es que no siempre existe coincidencia en la manera de determinar la utilidad del negocio y la renta gravable. Así ocurrirá, en ciertos casos, con las provisiones para malas deudas, el pago de algunas indemnizaciones, el gasto en vehículos destinados a la dirección de la empresa y muchos otros supuestos similares.

La ley agrega que el límite no es aplicable a:

a) Las empresas del sistema financiero $y$ de seguros.

b) Contribuyentes cuyos ingresos netos en el ejercicio sean menores o iguales a 2500 UIT —en el ejercicio 2021, S/ 11,000,000.00—.

Eso significa que en las empresas a que se refiere el inciso b) no importará si los endeudamientos son con partes vinculadas o con terceros independientes, ni cuál es la proporción que guardan respecto del patrimonio neto o de la relación que exista entre los intereses y el EBITDA, pues la restricción no habrá de aplicarse en ningún caso. 
Ahora bien, como suele ocurrir cuando la ley establece consecuencias en función de alcanzar o no una suma específica, ciñéndonos al texto literal sería forzoso concluir que la restricción operará aun cuando los ingresos netos de las empresas excedan en un sol al monto referencial, lo que daría lugar a que en dos empresas de situación esencialmente similar, se proceda de manera completamente distinta.

De otro lado, también en función de la literalidad es válido interpretar que los efectos no deberían aplicarse si los actos u operaciones se llevan a cabo por un conjunto de diversas sociedades jurídicamente independientes, pero que tienen como accionistas a las mismas personas o partes vinculadas. Como quiera que la ley no contiene ninguna salvedad con relación a esta hipótesis, podría sostenerse que si ninguna de tales empresas cuenta con ingresos que superan el límite fijado, todas ellas estarían excluidas de la restricción, a pesar de su conexión accionaria. Nótese que, por ello, la disposición podría conducir al efecto no querido de atomización de los negocios.

La fijación de determinada cantidad concreta para quedar al margen de la prohibición también obliga a pensar de inmediato sobre lo que sucedería con una empresa cuyos ingresos, según sus libros y declaraciones, no exceden del monto indicado y, por ello, considera que se encuentra fuera de la restricción y que puede deducir como gasto todos los intereses generados por sus operaciones de crédito.

No obstante, como ocurre con frecuencia, durante la fiscalización la Administración Tributaria podría sostener que la empresa no ha incluido determinados importes que debieron imputarse como devengados en el ejercicio materia de revisión. Con ese reparo los ingresos podrían exceder del límite y, por lo tanto, la materia imponible se incrementaría no solo en el monto de esa específica observación sino que ella tendría el importante efecto de obligar a añadir los intereses que exceden del $30 \%$ del EBITDA y que fueron deducidos por la empresa al estimar que se encontraba fuera del impedimento.
El cuestionamiento del fisco sobre cualquier extremo que signifique reparo por omisión de ingresos, generaría consecuencias en la deducibilidad de los intereses si la posición del contribuyente sólo tiene como base la cuantía de lo cobrado o por cobrar.

Ahora bien, según lo dicho, la limitación no se aplica a las empresas cuyos "ingresos netos" no excedan del monto indicado; pero cabe preguntarse, ¿qué debemos entender por ese concepto? Como quiera que la nueva regla no contiene definición propia, debemos asumir que el legislador considera como tal la que fluye del artículo 20 de la Ley del Impuesto a la Renta:

"El ingreso neto total resultante de la enajenación de bienes se establecerá deduciendo del ingreso bruto las devoluciones, bonificaciones, descuentos y conceptos similares que respondan a las costumbres de la plaza".

Nótese que el texto transcrito está referido sólo al resultado de la enajenación de bienes, lo que parecería no considerar el caso de la prestación de servicios u otras actividades que no están comprendidas en esa expresión. Por lo tanto, resulta válido remitirse a lo dispuesto por el artículo 85 de la Ley del Impuesto a la Renta, que al referirse a los pagos a cuenta señala:

"Para efecto de lo dispuesto en este artículo, se consideran ingresos netos el total de ingresos gravables de la tercera categoría, devengados en cada mes, menos las devoluciones, bonificaciones, descuentos y demás conceptos de naturaleza similar que respondan a la costumbre de la plaza".

Como puede apreciarse la redacción del artículo 85 parece omnicomprensiva - aunque dirigida a regular los pagos mensuales a cuenta- porque alude a todos los ingresos gravables y no solo a los que derivan de determinadas operaciones. En consecuencia, al carecer de una descripción específica, puede concluirse que para establecer si la empresa, por esta razón, está o no excluida de la restricción a la deducción de intereses, se debe considerar sólo el conjunto de los ingresos afectos al impuesto.

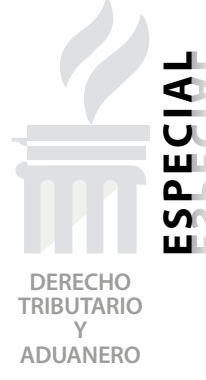

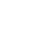


El asunto tiene importancia, entre otros supuestos, para el caso en que una sociedad cuenta con algunos ingresos no gravados, como ocurre con la que decide invertir en el capital de otras sociedades. En esa hipótesis, la empresa accionista percibirá dividendos que, por mandato de la ley, no dan lugar al impuesto a la renta, lo que permitiría interpretar que no deben computarse al establecer la limitación a la deducción de intereses.

Debe recordarse que, según la exposición de motivos, el EBITDA se ha construido sobre base tributaria, por lo cual es posible concluir que la suma que sirve como referencia para la exclusión debe ceñirse a la misma base. Ello significaría que si los montos obtenidos por las actividades propias del giro no superan dicho factor, la empresa no estaría sujeta a la limitación, aun cuando adicionalmente perciba dividendos $u$ otro tipo de renta inafecta o exonerada que, apreciados en conjunto, superen el margen señalado.

Igualmente, cabe preguntarse si para los mismos propósitos debería incluirse la eventual indemnización que una empresa reciba de otra por daño emergente, concepto que, como sabemos, no tiene en nuestro ordenamiento la naturaleza jurídica de renta $y$, por lo tanto, no forma parte de la materia imponible ni da lugar al pago del tributo. Asimismo, podría hacerse referencia a los intereses que abona el Estado cuando devuelve impuestos abonados en exceso o indebidamente y que constituyen ingresos que tampoco califican como renta gravable.

Los ejemplos podrían multiplicarse pero, en resumen, estimamos que la noción de ingresos netos únicamente debería comprender aquellos susceptibles de ser gravados con el impuesto porque, como ya se indicó, la exposición de motivos señala que la norma se ha estructurado sobre base tributaria, por lo que resultaría congruente concluir que también para estos fines sólo debe tomarse en cuenta la renta afecta. No obstante, sería deseable que se efectuaran precisiones para evitar posibles conflictos entre el fisco y los contribuyentes.
El límite tampoco es aplicable a:

c) Contribuyentes que desarrollen proyectos de infraestructura pública, servicios públicos, servicios vinculados a estos, investigación aplicada y/o innovación tecnológica en el marco del Decreto Legislativo 1224 -sustituido por el Decreto Legislativo 1362-.

d) Intereses de endeudamientos para el desarrollo de proyectos de infraestructura pública, servicios públicos, servicios vinculados a estos, investigación aplicada y/o innovación tecnológica, bajo la modalidad de Proyectos en Activos en el marco del citado Decreto Legislativo.

e) Intereses de endeudamientos provenientes de la emisión de valores mobiliarios representativos de deuda que se realicen por oferta pública primaria en el territorio nacional, sean nominativos y la oferta se coloque en un número mínimo de cinco inversionistas no vinculados al emisor.

La norma establece que los intereses señalados en los acápites d) y e) serán computables para calcular el límite establecido, pero son deducibles aun cuando excedan el referido límite. Ello significa, en definitiva, que si los endeudamientos de un contribuyente están referidos exclusivamente a ese tipo de obligaciones, los intereses que se generen siempre serán deducibles, sea cual fuere su monto. Ahora bien, si además existieran otros endeudamientos que dieran lugar a que el conjunto de intereses -incluyendo los previstos en d) y e) - superara el límite establecido, la no deducibilidad incidirá únicamente en los derivados de esos otros créditos.

El legislador cuidó siempre de referirse a endeudamientos y no solo a préstamos o mutuos, es decir ha utilizado un concepto genérico, de manera que la limitación podría comprender también los intereses que se pagan por las compras de mercadería a plazos que realiza un comerciante. Los términos amplios en que está formulada la norma permitiría interpretar que también en este caso opera la limitación, en la 
medida que la empresa deudora no se encuentre en alguno de los supuestos de excepción.

Como nota al margen, es pertinente señalar que si los créditos se capitalizan, se generan efectos equivalentes a los que derivan de la cancelación de la deuda. Después de esa operación, la empresa que era deudora ya no tendría intereses que pagar - ni deducir- pues emitiría acciones a favor de quien era acreedor y que, así, se convertiría en socio. Si posteriormente tal empresa decidiera reducir su capital respecto de ese socio específico, la devolución hasta por el valor nominal de las acciones no sería ingreso afecto para el perceptor; y el eventual exceso sobre ese monto tendría naturaleza de dividendos gravados si el accionista de que se trata fuera una persona natural - residente o no en el Perú-. En cambio, si fuera una persona jurídica domiciliada, ese dividendo no estaría sujeto al impuesto a la renta mientras no se produzca su redistribución.

Cabe destacar que en varios países de Latinoamérica la limitación sólo opera cuando se trata de endeudamientos entre partes vinculadas. En Colombia se aplica para créditos con cualquier tercero y con la ratio 3 a 1 sobre el patrimonio. En España también se aplica con vinculados y no vinculados, tomándose como referencia el $30 \%$ sobre EBITDA, que —según lo expuesto- es el mismo criterio que ha seguido nuestra legislación, de tal manera que estamos asumiendo una posición que corresponde a un país desarrollado y que resulta un tanto incongruente para el Perú donde existe un elevado porcentaje de economía informal.

\section{DEFINICIÓN LEGAL DEL CONCEPTO DE DEVENGO}

La Ley del Impuesto a la Renta, artículo 57, señala que "las rentas de tercera categoría se consideran producidas en el ejercicio comercial en que se devenguen", de manera que se trata de una noción que tiene el importante efecto de establecer el periodo al cual deben atribuirse los ingresos y gastos en la actividad empresarial.

Sin embargo, la norma simplemente aludía al concepto pero no contenía una definición del mismo, lo que a lo largo del tiempo ha motivado amplias discusiones entre fisco y contribuyentes. Cada vez que se producía una discrepancia sobre este extremo y otros similares, la Administración y el Tribunal Fiscal han recurrido a reglas contables que, en ocasiones, resultan imprecisas, por lo que pueden dar lugar a interpretaciones contradictorias.

Si quienes deben cumplir con la ley tributaria se ven obligados a remitirse a términos técnicos que no siempre son unívocos, su empleo puede generar inseguridad jurídica ${ }^{2}$ cuando tienen estrecha vinculación con la cuantificación de la renta y, obviamente, con la determinación del monto del tributo a pagar.

Es usual que las características y modo de aplicación de las normas internacionales de contabilidad se decidan en el exterior, lo que puede dificultar un enfoque correcto en nuestro país.

Como un modo de superar esas dificultades, el concepto de devengo se ha incorporado a la ley, de manera que cualquier variación que se realice en el futuro, tendría que hacerse a través de una expresa modificación de esa norma. Debe recordarse que, conforme a la Constitución, las leyes referidas a tributos de periodicidad anual, como el impuesto a la renta, solo entran en vigencia a partir del 01 de enero del año siguiente a su publicación. Con ello se debería ganar en certeza y estabilidad, pues la definición persigue que pueda determinarse el periodo al que debe imputarse un ingreso, sin necesidad de recurrir a las regulaciones existentes en otros ámbitos. Los criterios admitidos se mantendrán mientras no se produzca la variación legal con los requisitos

2. La seguridad jurídica es la razón fundamental para incorporar la definición del concepto de devengo en la Ley del Impuesto a la Renta, según se indica en la Exposición de Motivos del Decreto Legislativo 1425. 
y formalidades previstos en el ordenamiento jurídico.

Siguiendo este precedente, consideramos que resultaría positivo tratar de conseguir que los conceptos contables que más se utilizan en relación con el Impuesto a la Renta sean descritos en disposiciones legales específicas, de modo que aun cuando desde el punto de vista técnico una misma expresión pudiera tener diversas acepciones, para fines impositivos podríamos ceñirnos exclusivamente al texto previsto por el legislador, evitando los conflictos que se generan cuando hay imprecisión sobre el sentido de algunas nociones técnicas que inciden en la cuantía de la renta.

En tiempos recientes este tipo de dificultades se ha presentado, en los hechos, con las NIIF -Normas Internacionales de Información Financiera- que en algunas circunstancias exigen contabilizar ciertos bienes "a valor razonable", concepto que no es muy preciso pero que usualmente resulta distinto del valor histórico. Al respecto, es ilustrativo lo ocurrido con el ITAN ${ }^{3}$, tributo cuya materia imponible está constituida por el patrimonio neto de la empresa al cierre del ejercicio anterior, disposición que dio lugar a discrepancias sobre los importes a tener en cuenta; es decir, si la base gravable debe surgir del acatamiento a dichas normas internacionales o si se debe seguir considerando el valor histórico. Cuestionamiento similar se ha suscitado con relación al importe que debe considerarse al computar la depreciación de los bienes del activo fijo.

Sobre el particular, la Administración interpretó que para calcular la materia imponible del ITAN, debía recurrirse al denominado valor razonable, que era superior al valor histórico pero, paralelamente, concluyó que el primero no debía servir de base para la depreciación. Planteada la controversia, el Tribunal Fiscal interpretó que las normas del ITAN aludían al valor histórico y que, por lo tanto, este es el que debía utilizarse para los fines del impuesto y no el derivado de las NIIF. La decisión se apoyó, sustantivamente, en la literalidad del texto legal, confirmando así la conveniencia de contar con una norma jurídica específica que defina para propósitos impositivos las nociones contables de aplicación más frecuente en este campo.

En cuanto a la base para calcular la depreciación tributaria, siempre se ha considerado que debe tomarse en cuenta lo dispuesto por el artículo 41 de la Ley del Impuesto a la Renta, conforme al cual:

"Las depreciaciones se calcularán sobre el costo de adquisición, producción o construcción o el valor de ingreso al patrimonio de los bienes o sobre los valores que resulten del ajuste por inflación..."

Es por esa razón que, para fines de la depreciación tributaria se prescinde de los mayores valores derivados de la revaluación de activos que autoriza el artículo 228 de la Ley General de Sociedades donde se precisa que los bienes del activo de la sociedad:

"Son amortizados o depreciados anualmente en proporción al tiempo de su vida útil y a la disminución de valor que sufran por su uso o disfrute. Tales bienes pueden ser objeto de revaluación, previa comprobación pericial".

El Reglamento de la Ley del Impuesto a la Renta —artículo 14 inciso b-, cuida de señalar que:

"El mayor valor resultante de dicha revaluación, no dará lugar a modificaciones en el costo computable ni en la vida útil de los bienes y tampoco será considerado para el cálculo de la depreciación (...)"

Las situaciones indicadas ponen en evidencia las dificultades que los conceptos de técnica contable pueden generar en la aplicación de la ley tributaria, al dar lugar a interpretaciones disímiles, por lo que resulta plausible que una norma jurídica delimite su sentido y alcances. Naturalmente,

3. Nota del editor: siglas del Impuesto temporal a los activos netos. 
ello debe hacerse de manera tan clara y precisa como sea posible, de manera que para adoptar una posición determinada frente a cierto caso concreto sea suficiente remitirse a la disposición que recoge o describe el aspecto que interesa.

Parece adecuado que los pasos iniciales para marcar esa tendencia se den tratando de definir lo que debe entenderse por devengo. Debemos recordar que sobre esta materia SUNAT y el Tribunal Fiscal no siempre han mantenido un criterio único y, con frecuencia, el Colegiado ha señalado que si bien la ley no contiene una definición de ese concepto, puede recurrirse a la doctrina contable que ha establecido las características siguientes:

a) Requiere que se hayan producido los hechos sustanciales generadores del ingreso o gasto.

b) Requiere que el derecho al ingreso o compromiso de gasto no esté sujeto a condición de que pueda hacerlo inexistente.

c) No se requiere actual exigibilidad o determinación ni fijación de término preciso para su pago.

d) Puede ser obligación a plazo y de monto no determinado.

Así, por ejemplo, tratándose de intereses generados por créditos, estos tienen que entenderse devengados por el simple transcurso del tiempo. No obstante, en ciertos casos el Tribunal Fiscal ha recurrido a la $\mathrm{NIC}^{4} 18$ para señalar que tales ingresos sólo deben reconocerse cuando exista certeza razonable en cuanto al monto que efectivamente se va a obtener. Sin embargo, rechazó ese criterio cuando se trató de los denominados "intereses en suspenso" que registran las entidades financieras y que corresponden a los intereses moratorios que se generan luego de vencidos los plazos otorgados al deudor sin que este haya cancelado la obligación principal ni los intereses compensatorios.

La posición del Tribunal Fiscal es distinta a la seguida por la Superintendencia de Banca, Seguros y Administradoras de Fondos de Pensiones, para quien los "intereses en suspenso" no tienen que considerarse devengados ni como parte de la utilidad del ejercicio de las empresas del rubro financiero, por lo que varias de estas concluyeron que no deberían formar parte de la renta imponible.

En vista del temperamento adoptado por los organismos de la Administración, las empresas afectadas recurrieron al Poder Judicial y, en el caso de una de ellas, la Corte Suprema resolvió que los denominados "intereses en suspenso" no se consideran devengados precisamente por la falta de certeza sobre el monto que efectivamente habrían de obtener los acreedores $y$, por lo tanto, estableció que no debían formar parte de la renta imponible.

Sin embargo, la falta de regulación específica, que da lugar - como hemos dicho- a varias interpretaciones posibles, ha hecho que la propia Corte Suprema en un caso similar adopte una tesis contraria, evidenciando así la falta de previsibilidad sobre el sentido de la decisión de los órganos llamados a resolver, generando inseguridad jurídica en el círculo de entidades financieras.

En razón de esas dificultades y para que el panorama quedara claro, el legislador se vio obligado a precisar —Decreto Legislativo 979, Segunda Disposición Complementaria Final- que los "intereses en suspenso" deben ser atribuidos al ejercicio en que son percibidos, criterio que se encuentra definido de la manera siguiente:

"Las rentas se considerarán percibidas cuando se encuentren a disposición del beneficiario, aun cuando éste no las haya cobrado en efectivo o en especie" - Ley del Impuesto a la Renta artículo 59-. 
Este tipo de circunstancias hace que resulte conveniente, como hemos dicho, la definición legal de los conceptos contables que son utilizados de manera frecuente en el Impuesto a la Renta aplicable a empresas. En muchos casos similares la falta de pago o el pago de una suma menor a la que realmente correspondía tiene su origen en regulaciones oscuras, dudosas o susceptibles de más de una interpretación, no obstante lo cual únicamente en contadas oportunidades el Tribunal Fiscal ha recurrido, de oficio, a lo dispuesto en el artículo 170 del Código Tributario, conforme al cual no procede la aplicación de sanciones ni intereses cuando la deuda tributaria no se hubiese pagado como producto de la interpretación equivocada de una norma.

Conforme al Decreto Legislativo 1425, los ingresos se devengan cuando se han producido los "hechos sustanciales" para su generación, siempre que el derecho a obtenerlos no esté sujeto a una condición suspensiva, independientemente de la oportunidad en que se cobren y aun cuando no se hubieran fijado los términos precisos para su pago.

Tratándose de la enajenación de bienes, se considera que se han producido tales "hechos sustanciales" cuando el adquirente asuma el control o transfiera el riesgo de los bienes, lo que ocurra primero. Se entiende que el adquirente asume el control de los bienes cuando, como regla general, tenga derecho a decidir sobre su uso y a obtener los beneficios que generen.

A efectos de definir si el adquirente tiene el control de los bienes, se ha establecido que es necesaria la aplicación de la NIIF 15, la cual regula los ingresos de actividades ordinarias procedentes de contratos con clientes, en tanto no se oponga a la Ley. Con el evidente propósito de dejar en claro el sentido de la disposición, se ha precisado que debe tomarse en cuenta la versión de la NIIF 15 oficializada mediante resolución del Consejo Normativo de Contabilidad $N^{\circ}$ 002-2018-EF/30, lo que elimina la incertidumbre que se suele presentar cuando el factor de referencia ha variado en el momento que acontece el hecho que se analiza.
No obstante, cuando la contraprestación o parte de ésta se fije en función de un evento que se producirá en el futuro, el ingreso se devenga cuando aquel ocurra. Si parte de la contraprestación se pacta en función de un hecho futuro, esa parte se devenga cuando se presente el supuesto. El Reglamento acierta al señalar que se considera que existe hecho o evento futuro cuando la contraprestación se determina, entre otros casos, en función de las ventas, unidades producidas o utilidades obtenidas. No se incluye, entre otras, las situaciones en que el importe de la contraprestación está supeditado a la verificación de la calidad, características, contenido, peso o volumen del bien vendido que implique un ajuste posterior al precio pactado.

Sin embargo, existen algunas dudas cuando se trata de bienes exportados - como sucede en el caso de los minerales- que tienen cotización internacional y cuyo precio se pacta en función del valor promedio que arroje determinada Bolsa en un momento del futuro, a pesar de que ya se han producido los "hechos sustanciales" a que alude la ley, pero sin que a la fecha de celebración del contrato resulte posible conocer el monto a que ascenderá la contraprestación. Es cierto que en algunos casos se suele pactar una "liquidación provisional" cuyo importe no necesariamente podría calificarse como contraprestación parcial, pues en razón de la cotización que se tome como referencia podría ocurrir que el vendedor resulte obligado a devolver una parte del importe recibido.

Por lo tanto, sería deseable señalar expresamente que en estos casos el devengo del ingreso se produce solo en el momento que el precio queda determinado con arreglo a la cotización internacional que ha sido prevista en el contrato como referente.

Este extremo tiene importancia porque, como ya se explicó, la incorporación del ingreso a la renta bruta y el pago del impuesto que resulte, deben efectuarse en el ejercicio en que se considere producido el devengo. Podría ocurrir que el embarque de los bienes se realice en 
un determinado periodo, pero si el ingreso es atribuible a otro del futuro, solo en este se producirán consecuencias tributarias. Asimismo, el concepto tiene significación para establecer la base de cálculo de los pagos mensuales a cuenta, pues estos se computan sobre los ingresos devengados en el año.

Tratándose de servicios de ejecución continuada, la ley establece que:

a) Cuando se pacten por tiempo determinado, los ingresos se devengan en forma proporcional al tiempo pactado para su ejecución, salvo que exista un mejor método de medición de la ejecución del servicio, conforme a la naturaleza y características de la prestación.

b) Cuando se pacten por tiempo indeterminado, los ingresos se devengan considerando el mejor método de medición de su ejecución, conforme a la naturaleza y características de la prestación.

Debe advertirse que una regulación de naturaleza tan laxa puede ser una fuente de interpretaciones discrepantes y dar lugar a los problemas que, precisamente, se trata de evitar. Sería deseable que se introdujeran algunas precisiones porque la ausencia de definición es tan mala -o peor- que tener una que resulta imprecisa, incompleta u oscura.

La nueva norma señala que, en caso los contribuyentes omitan acreditar la pertinencia del método utilizado y el sustento de su aplicación, la SUNAT puede emplear el que considere conveniente, acorde con la naturaleza y características de la prestación. Por lo tanto, parecería que no se trata sólo de sostener que el método aplicado es pertinente sino que, además, la Administración debe coincidir con el criterio adoptado por la empresa contribuyente, aceptando que es el "mejor" para el caso concreto. Como esta regla podría ser otra fuente de probables discrepancias que deberían evitarse, los dispositivos legales que se expidan tendrían que ofrecer tantos detalles como fuera necesario para permitir que todos puedan coincidir en determinar el método más adecuado, tomando en cuenta el tipo de servicios y otras circunstancias que se estimen relevantes.

De otro lado, ¿cuándo debe acreditarse la pertinencia del método utilizado? Si es al producirse la fiscalización y la administración no comparte la posición del contribuyente, es muy poco lo que habríamos avanzado, pues se mantendría latente la posibilidad de desencuentros entre la empresa y la entidad acotadora, situación que claramente no conviene a nadie. Por ello, sería muy útil que la norma introdujera precisiones adicionales para tratar de alcanzar la mayor certeza posible o, alternativamente, que la autoridad tributaria emita pronunciamientos señalando cuáles son los métodos que se consideran pertinentes para determinado género de actividades y prestaciones.

Finalmente, cabe preguntarse qué sucedería si del análisis de lo pactado entre empresas se concluye que el mejor método para medir un determinado servicio de ejecución continuada es el de la retribución en función de horas hombre, pero que en aplicación de las normas contables resulta que sería más adecuado hacerlo en función de horas máquina ¿debe prevalecer la conclusión que fluye del contrato o la que se desprende de la contabilidad?

Situaciones como la expuesta confirman que la falta de parámetros específicos para establecer el mejor método de medición, puede producir inseguridad jurídica que, precisamente, es lo que se debe evitar, de manera que siendo conveniente que las normas legales contengan la definición de los conceptos contables que tienen más relación con la renta empresarial, debe hacerse el mayor esfuerzo para que los contribuyentes encuentren en las disposiciones que se publiquen una fuente de certeza para cada caso concreto.

\section{ENAJENACIÓN INDIRECTA DE ACCIONES}

Al tratar sobre la base jurisdiccional del impuesto a la renta, la ley establece que los contribuyentes no domiciliados sólo están obligados a tributar por sus rentas de fuente peruana. Hasta hace algún tiempo la ganancia obtenida en la enajena- 
ción de acciones sólo se consideraba como renta de fuente nacional cuando versaba sobre las emitidas por empresas constituidas en el país.

De acuerdo con esa regulación, si las acciones representativas del capital de una sociedad registrada en el Perú eran de propiedad de una holding establecida en un paraíso fiscal y si las acciones de esta pertenecían a un no domiciliado en el país, éste podía limitarse a vender las acciones emitidas por la sociedad del exterior sin que ello precipitara el hecho imponible, ya que la transferencia estaba referida a los títulos de una empresa no constituida en el Perú. Se trataba de una persona no domiciliada que no obtenía renta de fuente peruana y, por ello, respetando el principio de legalidad nos encontrábamos frente a una operación no gravable, ya que el beneficio obtenido no estaba específicamente descrito en la ley como renta de fuente nacional.

Por ello, como sucedió en otros países de Sudamérica, en el Perú se modificó la ley para incluir como de fuente local la ganancia obtenida en la enajenación indirecta de acciones, disponiéndose que ella se produce cuando se transfieren las emitidas por una persona jurídica no domiciliada que, a su vez, es accionista de una sociedad constituida en el país si:

a) En cualquiera de los doce meses anteriores a la enajenación, el valor de mercado de las acciones de las personas jurídicas domiciliadas, de titularidad directa o indirecta de la persona jurídica no domiciliada - cuyas acciones serán enajenadas-, equivale al $50 \%$ o más del valor de mercado de todas las acciones representativas del capital de esta última.

El legislador entiende que en estos casos el precio de las acciones de la empresa del exterior se explica por el valor que tienen las acciones de las que es titular - directa o indirectamente - en la sociedad constituida en el Perú, de manera que en esa estructura la circunstancia gravada no se presenta en todos los casos en que la empresa del exterior es accionista de una compañía local. Por lo tanto, a pesar que la holding cuente con acciones de sociedades peruanas, no habría lugar al tributo si, por ejemplo, la entidad no domiciliada tuviera en su activo títulos emitidos por sociedades de terceros países que registren patrimonios más significativos que los de la empresa peruana. En esa hipótesis, dichas otras sociedades tendrían en el valor de las acciones de la holding una incidencia mayor que la producida por los títulos de la sociedad domiciliada en el país. En otras palabras, si en la valorización de las acciones de la empresa del exterior, los títulos emitidos por la compañía nacional no tienen gran trascendencia económica -en los términos descritos por la norma-, no se configuraría renta de fuente peruana y, por ello, no se generaría la obligación de pagar el impuesto. Como veremos más adelante, esta situación ha sido materia de ajustes en el texto legal, para circunstancias específicas.

b) En un periodo de doce meses se enajenen acciones que representen el $10 \%$ o más del capital de la persona jurídica no domiciliada.

Es necesario puntualizar que el texto no era absolutamente claro y que una de las interpretaciones posibles permitía concluir que este requisito tenía que cumplirse respecto de las operaciones efectuadas por cada socio, pero también podría considerarse que debían computarse las operaciones llevadas a cabo por todos los accionistas.

Debe advertirse que, a diferencia de lo que ocurre en otra regulación comparable - "transparencia fiscal internacional"si se interpretara que el cómputo de las operaciones tenía que hacerse respecto de cada accionista, podría ocurrir que no se superara el límite establecido, a pesar de existir una pluralidad de enajenaciones realizadas por diversos socios que eran partes vinculadas y que, por eso, podrían estar representando un mismo interés.

En lo que se refiere a la forma de establecer 
si se ha producido la enajenación del 10\%, la ley señala ahora que deben computarse las transferencias simultáneas o sucesivas efectuadas por el enajenante y sus partes vinculadas. En estos casos, cada uno de los sujetos que concurrieron para alcanzar enajenaciones por el $10 \%$ o más del capital, será contribuyente por la porción que hubiera transferido, de modo que resulta claro que el cálculo debe hacerse con relación a las operaciones de cada socio pero en el cómputo deben considerarse las operaciones llevadas a cabo por los vinculados.

Según la exposición de motivos, el propósito de esta disposición es evitar que las grandes empresas puedan eludir el impuesto, configurando las enajenaciones a través de distintas compañías relacionadas, de modo que ninguna de ellas llegue de manera individual al límite del 10\%, a pesar que el conjunto de transacciones superará ese porcentaje.

Por lo tanto, la modificación aclara y amplía la forma de establecer cómo se alcanza el límite indicado. Sin embargo, debe notarse que si las transferencias por analizar se llevan a cabo en el exterior y comprenden a personas no domiciliadas, pueden generarse dificultades para establecer la realidad de los hechos y como quiera que, obviamente, nuestras autoridades tributarias no cuentan con atribuciones para inspeccionar a empresas que operan fuera del país, las regulaciones sobre partes vinculadas pueden dar lugar a inconvenientes para concluir si se presentan las circunstancias que configuran la condición a que se alude. Es probable que estas dificultades se atenúen con las recientes reglas referidas al "Beneficiario Final", las que en algunos casos permitirán al fisco verificar la existencia del nexo que se busca establecer.

En lo que se refiere a la clase de operaciones que dan lugar a enajenación indirecta de acciones, puede observarse que existe por lo menos una contradicción terminológica. En efecto, la exposición de motivos in- dica que podrán incluirse las transferencias de acciones que se efectúen a título gratuito o utilizando instrumentos financieros que conlleven su transferencia, siendo así que por definición de la propia ley —artículo 5- el concepto enajenación implica siempre un acto de disposición por el que se transmite el dominio a título oneroso, de modo que comprender las transferencias gratuitas podría evidenciar una falta de coherencia.

Sin embargo, no puede descartarse que el propósito del legislador haya sido incluir el cómputo de las transferencias a título gratuito sólo para establecer si se cumple o no con el test del $10 \%$, pero no significa que tienen que considerarse como enajenación. Dentro de esta tesis, todas las transferencias deben tomarse en cuenta para determinar si se alcanzó el referido porcentaje, pero luego de ello únicamente habrá hecho imponible cuando se trate de una operación onerosa.

De cualquier manera, tratándose de un aspecto tan importante estimamos que para evitar innecesarias acotaciones y reclamaciones, debería efectuarse la necesaria precisión.

Por otra parte, debe destacarse que la norma incluye un nuevo supuesto de enajenación indirecta que no requiere el cumplimiento de los requisitos de $50 \%$ o más del valor de mercado ni la transferencia del $10 \%$ o más de las acciones en un periodo de 12 meses, sino que resulta condición suficiente que el importe de las acciones locales enajenadas de manera indirecta en un periodo cualquiera de 12 meses sea igual o mayor a 40,000 UIT.

En concordancia con los cambios señalados previamente, este nuevo supuesto también contempla las ventas que hubieran realizado de manera simultánea o sucesiva el enajenante o sus partes vinculadas y que en conjunto, en el período de 12 meses, lleguen al importe mencionado.

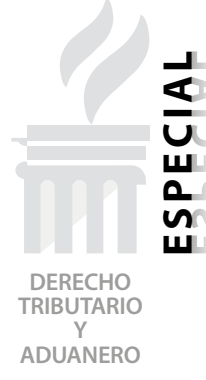

\section{.}


Según la exposición de motivos, lo que se persigue con esta modificación es gravar enajenaciones indirectas de acciones peruanas por montos que son materiales para el fisco de nuestro país aunque, eventualmente, para el enajenante - de ordinario una compañía multinacionalno representen un porcentaje significativo del valor de las acciones de la empresa no domiciliada que son materia de transferencia directa. Como se sabe, el factor de referencia - UIT_ - varía año a año, de tal forma que el monto a considerar podría ser distinto en cada ejercicio.

Con independencia del valor pactado en la enajenación de las acciones de la empresa del exterior, se ha previsto que en el Perú el ingreso gravable no puede ser inferior al valor de mercado de las acciones que se enajenen indirectamente -es decir de las acciones peruanas- que es el que nuestro ordenamiento toma como importe mínimo.

La precisión se explica porque podrían existir empresas del exterior cuyas acciones se enajenen por su real valor de mercado, pero que éste resulte reducido no en razón de las acciones peruanas que podrían ser valiosas, sino que el impacto negativo se origine por inversiones hechas en acciones emitidas por sociedades constituidas en terceros países y que han sufrido pérdidas significativas.

Al aplicarse la nueva regulación se gravaría por lo menos la utilidad que se configuraría al considerar como ingreso el que se habría obtenido si se tratara de la venta de las acciones locales, lo cual significa que si no están cotizadas en Bolsa, debe tomarse en cuenta el valor de participación patrimonial calculado sobre la base del último balance anual de la empresa emisora, que se obtiene dividiendo su patrimonio entre el número de acciones emitidas.

Finalmente, se señala que en aquellos casos en que se produzca una enajenación indirecta y el enajenante cuente con una sucursal o establecimiento permanente en el Perú, dicha sucursal o establecimiento permanente tendrá la condición de responsable solidario por el pago del tributo.

Debe destacarse que antes de esta modificación, la responsabilidad solidaria, en ciertas circunstancias, alcanzaba solo a la sociedad domiciliada emisora de las acciones objeto de la enajenación indirecta, lo que parecería suponer que dicha empresa local debería estar al corriente de las decisiones tomadas por los propietarios de las acciones emitidas por la holding del exterior. La nueva norma amplía tal responsabilidad a la empresa enajenante no domiciliada, que se haría efectiva a través de los referidos establecimientos con los que pudiera contar en el Perú y que, teóricamente al menos, pueden estar más involucrados con los acuerdos adoptados por su casa matriz. 